\title{
Downstream Competition, Foreclosure, and Vertical Integration
}

\author{
Gilles Chemla *
}

July 8, 2002

${ }^{*}$ University of British Columbia and CEPR. Correspondence: Faculty of Commerce, University of British Columbia, 2053 Main Mall, Vancouver, B.C. V6T 1Z2, Canada. E-mail: gilles.chemla@commerce.ubc.ca, tel: 1604822 8490, fax: 1604822 4695. I am particularly indebted to Patrick Bolton, Antoine Faure-Grimaud, Denis Gromb, John Moore, Patrick Rey, Jean Tirole, two anonymous referees and the coeditor for long conversations and/or very thoughtful comments which have greatly improved the quality of this paper. I am also grateful to Torkild Byg, Murray Carlson, Sorbas von Coester, Leonardo Felli, Michel Habib, Jan Mahrt-Smith, Raghuram Rajan, and seminar participants at the 11th World Congress of the International Economic Association, the 1996 North American Winter Meeting of the Econometric Society, the Canadian Economic Association 2000 Meetings, CSIC - Universitat Autonoma de Barcelona, Seminaire Fourgeaud (CERAS), HEC Graduate School of Management, London School of Economics, THEMA, University of British Columbia, University College of London, and Universitat Pompeu Fabra for helpful discussions on early drafts. All errors are mine. 


\title{
Downstream Competition, Forclosure, and Vertical Integration
}

\begin{abstract}
This paper analyzes the impact of competition among downstream firms on an upstream firm's payoff and on its incentive to vertically integrate when firms on both segments negotiate optimal contracts. We argue that the upstream firm is better off encouraging competition when the downstream firms have high bargaining power. We examine the interactions between vertical integration and competition among the downstream firms. The possibility of vertical integration may be a barrier to entry and may trigger strategic horizontal spin-offs or mergers. An upstream duopoly is better off with a competitive downstream industry, and a partially integrated structure may be anti-competitive.
\end{abstract}

JEL: D4, L1, L42.

Key words: contracts, bargaining, competition, foreclosure, vertical integration. 


\section{Introduction}

Monopolists have long been blamed for attempting to extend their market power to vertically related segments (Posner (2001)). In order to better understand the economic forces that may induce and enable monopolists to monopolize other segments, the literature on vertical relationships and market foreclosure has examined various mechanisms through which a firm with significant market power ends up reducing competition in vertically related markets. These mechanisms include take-it-or-leave-it exclusive-dealing contracts, (price) discrimination, and/or vertical integration (see Rey and Tirole's (1999) survey, hereafter RT). In this literature, an upstream firm can appropriate (a fixed fraction of) the downstream industry profit by using its bargaining power to impose vertical restraints on downstream firms. Since the downstream industry profit decreases with competition, the upstream firm is thus better off reducing competition in the downstream industry.

This paper shows that the argument that a monopolistic upstream firm is often tempted to monopolize downstream industry is sensitive to the specific bargaining games that are considered in existing papers. We point out that when the upstream firm has limited bargaining power, it may be tempted to encourage competition downstream in order to improve its bargaining position. Specifically, more fierce competition among downstream firms has two conflicting effects on the payoff to the upstream firm: it erodes the downstream industry profit, but it improves the upstream firm's negotiation position, i.e. it gets a larger share of a lower industry profit. As a result, more downstream competition increases the payoff to the upstream firm when the upstream firm has low bargaining power. Building on these results, we consider the possibility for the upstream firm to vertically integrate one downstream firm. Since the payoff to the upstream firm without integration depends on the level of downstream competition, and since vertical integration affects the total quantity supplied and the number of active downstream firms, the incentive for 
vertical integration depends on the market environment. We further analyze the impact of upstream competition on these results.

In our model, the downstream firms compete both to buy input from the upstream firm and to sell output to consumers. For each transaction, optimal tariffs contingent on the quantity exchanged are considered so that double marginalization is irrelevant. Hence, more fierce competition between downstream firms improves the upstream firm's bargaining position because it leads the downstream firms to make higher bids for the upstream firm's input. Each downstream firm sees itself as the marginal firm, and an increase in the number of downstream firms entails a higher cost of supplying the marginal downstream firm. In situations where the upstream firm has low bargaining power, it is better off with a more competitive downstream industry. This effect can be so strong that the upstream firm's incentive to favor competition can be higher than that of a social planner On the other hand, the upstream firm's incentive to vertically integrate a downstream firm in order to monopolize the downstream industry is sometimes lower than that of a social planner.

Papers particularly close in spirit to ours are Bolton and Whinston (1991, 1993) (hereafter BW) and especially Hart and Tirole (1990) (hereafter HT) who consider a framework where one or two upstream firms supply two downstream firms competing both for input and in the output market ${ }^{1}$. They analyze conditions under which vertical integration takes place, when it leads to market foreclosure, and when it is socially desirable. These papers, however, find that firms with market power have an incentive to restrict competition in vertically related markets and that they have too high an incentive for vertical integration. In this paper we point out that their results relies essentially on the assumption that the vertically related firms do not have significant bargaining power. For instance, HT considers take-it-or-leave-it contract offers from an upstream firm to downstream firms.

Our point that, when firms bargain over optimal contracts, more compe- 
tition in vertically related markets increases a firm's bargaining power contributes to different literatures. For instance, a firm or a country may want to buy input from several suppliers to obtain more attractive supply contracts. In particular, a firm may benefit from having several competing financiers in order to improve its bargaining power. This is to be contrasted with Rajan's (1992) theory of arm's-length debt where arm's-length debt reduces the creditors' bargaining power. In his paper, the lower bargaining position of creditors is due to their inability to acquire information about the borrower rather than more competition between creditors. Furthermore, we show that this argument holds for bargaining over optimal contracts rather than only simple linear contracts. Formally, our paper also contributes to the literature on competition in contracts. In our setup, the secrecy of transactions between the upstream firm and each downstream firm ensures that each downstream firm only considers its marginal, bilateral relationship with the upstream firm. As a result, the upstream firm cannot commit not to supply other downstream firms. When downstream firms make contract offers, the increasing cost of supplying downstream firms leaves the upstream firm with a surplus, and the constant marginal cost of production ensures that the downstream firms also obtain a positive payoff, since they still view their relationship with the upstream firm as a marginal, bilateral relationship. We then derive a unique Cournot equilibrium, which is to be contrasted with the multiple equilibria found in most existing papers with multiple principals (Bernheim and Whinston (1986a, 1986b), Klemperer and Meyer (1989), and Martimort (1996)). Biais, Martimort and Rochet's (2000) paper, which was developed independently, also finds, but for different reasons, that strategic, risk-neutral market makers competing in contracts to supply a risk-averse agent may benefit from limited competition due to the agent's private information about both his valuation and his hedging needs. Their result is driven by the information revealed by the trades, which ensures that unit prices increase with the quantities traded, and thus that the elasticity of the 
residual demand curve is finite.

The paper proceeds as follows. Section 2 presents the model. Section 3 describes the rent reduction and negotiation effects, deriving costs and benefits of downstream competition. The interactions between vertical integration and competition between downstream firms are examined in section 4 . Section 5 examines the impact of upstream competition on these results and it identifiies condition for vertical integration to lead to a monopolistic downstream industry output and to a competitive downstream industry output. Section 6 concludes.

\section{The Model}

An upstream firm $U$ produces an input that it can sell to $n \leq N$ potential downstream firms $D_{1}, \ldots, D_{n}$ competing in an output market. The inverse demand function in the output $Q \rightarrow P(Q)$ is assumed decreasing and concave: $P^{\prime}<0$ and $P^{\prime \prime}<0^{2}$. The downstream firms need one unit of the input to produce one unit of the homogeneous output. Downstream firm $D_{i}$ has a zero transformation cost and no alternative supply source.

To produce a good for downstream firm $D_{i}$, the upstream firm needs to bear the cost $f(i)$ of opening a specific line of production. For instance, this line of production can be thought of as a necessary step to produce an input which is compatible with $D_{i}$ 's technology. We denote $F(n)=\sum_{i=1}^{n} f(i)$ and we assume that $f(\cdot)$ increases with the number of lines of production which are open. The fact that this cost increases may reflect growing agency costs within the upstream firm when it expands. Once the line of production is open, $U$ can produce a number of units at a constant marginal cost $c$. Hence, producing a quantity $q_{i}$ for firm $D_{i} \operatorname{costs} C\left(i, q_{i}\right)=f(i)+c q_{i}$. We assume that $f(n) \leq\left[P\left(n q^{C}(n)\right)-c\right] q^{C}(n), \forall n \in\{1, \ldots, n\}$, where $q^{C}(n)$ is the Cournot quantity bought by one downstream firm when there are $n$ downstream firms on the market.

Our contractual assumptions are similar to those in HT and RT. 
Assumption 1 Downstream firms' production is not contractible.

There may be several technical reasons why parties might be unable or reluctant to sign such contracts. For instance, the units of input may be difficult to measure, e.g. in service industries. In addition, there may be a probability that a technological innovation or a shock creates an alternative source of supply whose use is not verifiable or decreases the upstream firm's cost. Hence, a contract may lead downstream firms to give away excessive rents to the upstream firm. The downstream firms may then be better off not signing contracts contingent on outputs ${ }^{3}$. Moreover, in our setup, the primary aim of such contracts would be to monopolize the market, which is likely to be forbidden by antitrust law.

Assumption 2 Contracts and transactions between the upstream firm and any of the downstream firms are not observable by the other downstream firms.

HT thoroughly justify these assumptions. In particular, they stress the difficulty for a downstream firm to "monitor or control shipments made by $[U]$ to other parties without having residual rights of control over the assets of $[U]$, including buildings, trucks and inventories." Given this assumption, contracts conditional on other contracts (in particular exclusive dealing contracts) are not feasible. When it negotiates with one downstream firm, the upstream firm cannot commit not to supply inputs to other downstream firms ${ }^{4}$. Since contracts are unobservable, there is no possible precommitment via a contract (Katz (1991)). More specifically, $U$ cannot induce the downstream firms to undertake ex post inefficient actions in the output market.

Furthermore, we assume that there is no trade between the downstream firms. This may be the case, for instance, when only the upstream firm has the technology to design the input for the use of each downstream firm or the ability to transport the input. 
The surplus generated is divided through bargaining over tariffs between the upstream firm and the downstream firms. The bargaining game between $U$ and $D_{i}$ is as follows: With probability $\alpha \in[0,1], U$ simultaneously makes each $D_{i}$ a take-it-or-leave-it offer of a tariff transfer $T_{U, i}(\cdot)$. Then, each $D_{i}$ either accepts or rejects the offer it was made. With probability $1-\alpha$, all downstream firms simultaneously make take-it-or-leave-it offers $\left.T_{i, U}(\cdot)\right\}, i=1, \ldots, n$ to $U$. Then, $U$ either accepts or rejects each offer. The parameter $\alpha$ can be thought of as the upstream firm's bargaining power ${ }^{5}$. For the sake of exposition, we restrict most of our discussion to the two polar bargaining powers. By continuity, the results with $\alpha=0$ hold for low values of $\alpha$ and the results with $\alpha=1$ hold with high values of $\alpha$ (see Chemla (2000)).

The timing of the game is as follows:

- In stage 1 , the upstream firm chooses the number $n \leq N$ of downstream firms which will be potentially active in further stages. The number of downstream firms picked by the upstream firms is public information.

- In stage 2 , nature draws whether the take-it-or-leave-it offer $T_{i}(\cdot)$ is made by $U$ or by each $D_{i}$. The take-it-or-leave-it offer is made and the parties that receive the offer choose either to accept it or to reject it. If an offer corresponding to a bilateral transaction between $U$ and $D_{i}$ is accepted, the corresponding $D_{i}$ then orders a quantity of input $q_{i}$ and pays $T_{i}\left(q_{i}\right)^{6}$.

- In stage 3, the downstream firms transform the input into an output, observe others' production and choose their prices at which the consumers buy this output.

Formally, stage 1 is not necessary to our main results. In its absence, we would simply consider how $U$ 's payoff depends on $n$. Stage 1 decisions reflect the idea that the upstream firm can specify technical characteristics which are necessary for compatibility reasons or communicate a particular technology in 
order to endogeneize downstream competition. Without knowing these characteristics or this technology, a downstream firm starts development too late to be able to produce in later stages. In other words, the upstream firm "qualifies" a set of downstream firms in stage 1, and it can commit to exclusive contracting by refusing qualification to all but one downstream firm. However, once the requisite technical specifications have been communicated to multiple potential distributors at the qualification stage, then exclusive dealing is not possible in stage 2 . In section 4 , we will also consider a vertical integration game, whereby stage 1 will be a vertical integration decision instead of the direct qualification stage, while the other stages will remain unchanged.

We assume that an (out-of-equilibrium) offer by $U$ to a downstream firm cannot affect this firm's beliefs about $U$ 's offer to another downstream firm. This is natural because the offers are secret and $U$ tries to extract as much rent as it can from each downstream firm. This assumption rules out any manipulation of beliefs and will guarantee the uniqueness of the pure strategy Perfect Bayesian Equilibria we shall derive. This assumption is discussed at length in McAfee and Schwartz (1993), HT and RT who call it "market-bymarket bargaining" or "passive conjectures".

When the quantity $q_{i}$ is exchanged against a transfer $T_{i}\left(q_{i}\right)$, we denote:

- $\pi_{i}=P(Q) q_{i}-T_{i}\left(q_{i}\right)$ downstream firm $D_{i}$ 's profit,

- $\pi_{U}=\sum_{i=1}^{n} T_{i}\left(q_{i}\right)-c Q-F(n)$ the payoff to the upstream firm (its reservation utility is normalized to 0 ),

- $C S=\int_{0}^{Q} P(x) d x-P(Q) Q$ the consumer surplus,

- $S W=\pi_{U}+\sum_{i=1}^{n} \pi_{i}+C S=\int_{0}^{Q} P(x) d x-c Q-F(n)$ the social welfare.

As a benchmark, we first turn to the case where the upstream firm's offers are publicly observable. These tariff offers would satisfy ${ }^{7}$ : 


$$
\begin{array}{cl}
\max _{\left(T_{U, i}(\cdot)\right)} & \sum_{i=1}^{n}\left[T_{U, i}\left(q_{i}\right)-c q_{i}-f(i)\right] \\
\text { s.t. } & q_{i} \in \arg \max P\left(q_{-i}+q_{i}\right) q_{i}-T_{U, i}\left(q_{i}\right) \\
& P\left(q_{-i}+q_{i}\right) q_{i}-T_{U, i}\left(q_{i}\right) \geq 0, \forall i \in\{1, \ldots, n\}
\end{array}
$$

In this case, the offers can perfectly manipulate the quantities $q_{i}$ keeping the downstream firms' participation constraints binding. Under complete information, $U$ can commit to sell a given amount of input to the industry and appropriate the whole industry surplus, which is maximized under the monopoly quantity (Mathewson and Winter (1984)). In equilibrium, the total quantity produced is (not surprisingly) the monopoly quantity $Q^{m}=\arg \max P(Q) Q-c Q$. Any allocation of the monopoly quantity among downstream firms is an equilibrium. Thus, the industry production and the consumer's surplus do not depend on $n$, while the payoff to the upstream firm and social welfare decrease with the number of downstream firms supplied by a correspondingly higher number of lines of production.

If, instead, the downstream firms were to make take-it-or-leave-it, publicly observable offers to the upstream firm, exclusive dealing contracts could be written. Downstream firms would compete in tariffs to obtain a franchise whereby the upstream firm would restrict its supply to the monopoly quantity. Hence, the upstream firm could obtain the entire monopolistic downstream industry profit. We shall see that the secrecy of transactions will prohibit this outcome.

\section{The Incentive to Favor Downstream Com- petition}

In this section, we show that the effect of downstream competition on the upstream firm's surplus and social welfare crucially depends on the distribution of bargaining powers. We identify the rent reduction (or output) and negoti- 
ation effects. We shall see that when its bargaining power is low enough, the upstream firm may be better off with a competitive downstream industry.

From now on, we assume that the transactions between the upstream firm and a downstream firm are not observable to other downstream firms. In this setup, we shall see that the upstream firm is unable to credibly commit to sell the monopoly quantity or not to supply some firms.

\subsection{The Equilibrium Quantities and Transfers}

Proposition 1 In equilibrium, the upstream firm supplies each downstream firm the Cournot quantity independently of the distribution of bargaining power.

The transfer from each downstream firm to the upstream firm is $P\left(n q^{C}\right) q^{C}$ if the offer is made by the upstream firm, and $c q^{C}+f(n)$ if the offer is made by the downstream firms.

Proof: See Appendix.

The secrecy of transactions prevents the upstream firm from committing its output to a level that is different from the Cournot quantity. This reduces the downstream industry surplus that cannot be monopolized. In particular, if exclusive-dealing contracts could be written then the upstream firm could make offers where it commits not to supply the Cournot quantity, and then appropriate the monopolistic downstream industry surplus if it has bargaining power, and get the downstream firms to bid for the franchise without dissipating any monopoly rents if downstream firms have bargaining power.

The total (Cournot) quantity increases with the number of downstream firms, but it is independent of bargaining power. The reason for this is simply that each party making an offer to its trading partner seeks to maximize the surplus from their bilateral relationship, regardless of the relationships between the upstream firm and the other downstream firms. Whatever the distribution of bargaining power, $U$ cannot commit in any way to restrain the quantity competition between the downstream firms ${ }^{8}$. 
When the upstream firm makes the take-it-or-leave-it offers, it appropriates the whole downstream industry Cournot profit. This makes it clear that the upstream firm suffers from the inability to commit to supply less than the Cournot quantity. More interestingly, when the downstream firms make the take-it-or-leave-it offers, they cannot prevent the upstream firm from opening another line of production and selling inputs to other downstream firms. This leads them to leave the upstream firm with a rent which increases with the number of firms.

In this simple environment, bargaining power does not affect production. It simply determines the distribution of the rents obtained for given output between upstream and downstream firms. These two features allow us to focus on the tradeoff between the redistribution of rents and the size of the rents.

\subsection{The Rent Reduction Effect}

When the upstream firm has all bargaining power, it appropriates the entire industry surplus. If there are more than one firms in the downstream market then more output is produced than in a monopoly and increasing total output by increasing the number of downstream firms leads to a rent reduction. We refer to this as the rent reduction effect of competition. When $n$ increases, total output and consumer surplus increase, but the payoff to the upstream firm $P(Q(n)) Q(n)-c Q(n)-F(n)$ decreases (since $Q>Q^{m}, P^{\prime}<0$ and $\left.P^{\prime \prime}<0,\left[P(Q(n))-c+P^{\prime}(Q(n)) Q(n)\right] Q^{\prime}(n)-F^{\prime}(n)<0\right)$. U appropriates the whole industry surplus which is maximized under monopoly. Therefore, when it has all the bargaining power, the upstream firm chooses $n=1$ potentially active downstream firms in stage 1, i.e. it forecloses the market, although this is undesirable from a social viewpoint ${ }^{9}$. 


\subsection{The Negotiation Effect}

We now turn to the case where the bargaining game is reduced to simultaneous contract offers from the downstream firms to the upstream firm. When making an offer, each $D_{i}$ expects that $n-1$ other downstream firms will be supplied, and that it will cost $c q_{i}+f(n)$ to the supplier to produce $q_{i}$ units of input. Hence, each $D_{i}$ 's offer and the number of units both increase with $n$. The key ingredient for the former result is $U$ 's increasing cost of opening additional lines of production. This ensures that the payoff to the upstream firm, $\pi_{U}(n)=$ $c Q+n f(n)-c Q-\sum_{i=1}^{n} f(i)=\sum_{i=1}^{n}[f(n)-f(i)]$, increases with $n$. We call this latter effect the negotiation effect ${ }^{10}$.

The intuition behind the negotiation effect can be understood as follows. Each $D_{i}$ has to offer the upstream firm $c q^{C}+f(n)$, which is the incremental cost of dealing with the marginal firm. Any offer that is below this incremental cost would lead $U$ to not supply the downstream firm. Hence, the payoff to $U$, $n f(n)-F(n)$, is increasing in $n$. As the number of downstream firms grows the upstream firm retains all the inframarginal benefits of supplying them all.

The negotiation effect increases the payoff to the upstream firm for two reasons. While a downstream monopolist would only have to pay the upstream firm the average cost of producing a quantity $Q$, negotiation with $n$ firms producing $Q$ brings payments of each of them closer to the incremental cost of producing $Q / n$ for each of them. In addition, the quantity purchased by downstream firms increases with $n$. Hence, an increase in downstream competition increases both the unit price of downstream firms' input and the total quantity sold to downstream firms. If the upstream firm makes the offer, the output effect of increased competition leads to a reduction in rents and therefore to a reduction in extracted surplus. If the downstream firms make the offers, increased competition enables $U$ to benefit from the negotiation effect, increasing both output and the average price for a given level of output.

Hence, in stage 1, the upstream firm publicly picks $n=N$ potentially active 
downstream firms. Since the upstream firm has no bargaining power, it favors competition (rather than foreclose the market) between the downstream firms to induce them to make higher offers. Thus, the upstream firm's choice of downstream competition crucially depends on its bargaining power ${ }^{11}$.

The negotiation effect leads downstream firms to make offers to $U$ which increase with the degree of competition as measured by the number of downstream firms. While it is modeled through an increasing cost of opening lines of production, such an effect is robust to a number of alternative specifications of the market environment and of the bargaining procedure. It should be noted, however, that our cost structure is particularly convenient in that it captures the higher cost of servicing a larger number of firms while leaving the upstream firm with the commitment problem mentioned above. With an increasing marginal cost of total production, instead of an increasing cost of opening an additional line of production, downstream firms' offers would be more complicated to describe. Ceteris paribus, the competition effect would be more extreme than in the present setting. Indeed, downstream firms might be tempted to make offers whereby they buy a quantity that excludes competitors and to produce the monopoly quantity. The increasing marginal cost of production would, under some circumstances, enable the upstream firm to commit not to supply more units of input to other downstream firms when this becomes too costly ${ }^{12}$. This ability to exclude competitors, that extends Aghion and Bolton's (1987) analysis of contracts as a barrier to entry, is further discussed in section 5 .

Analyzing the two polar cases of take-it-or-leave-it offers by the upstream and the downstream firms has enabled us to identify two antagonistic effects of competition. It follows that for intermediate bargaining powers there is a trade-off between these effects. More competition between downstream firms improves the upstream firm's negotiation position, but decreases the industry profit. When it has high bargaining power, the upstream firm appropriates a 
large share of the downstream industry profit while the effect of competition on the downstream firms' offers is not very important. It is thus better off facing a non competitive downstream industry. In contrast, when its bargaining power is low, it appropriates a small share of the industry profit in the absence of competition. Downstream competition enables the upstream firm to increase its share of the downstream industry profit by enhancing its bargaining power. The negotiation effect gives the upstream firm an incentive to enhance bargaining power at the cost of total rent.

\subsection{Social Welfare Implications}

The upstream firm's incentive to favor competition is, however, unrelated to social concerns. From a social viewpoint, the welfare-improving effect of an increase in competition clearly decreases in $n$ since the positive effect of increasing $n$ on consumer surplus decreases with $n$ and the cost of opening additional lines increases with $n$, More importantly from a policy viewpoint, we should wonder whether $U$ 's incentive to promote competition is too low from a social viewpoint. This can be done easily by comparing the upstream firm's payoff and $S W$. When $U$ makes the offers, given that $\pi_{i}=0$ for any $n$, and that $U$ bears all the cost of opening additional lines of production, the only difference with the objective of a social planner is that $U$ does not internalize the positive effect of more competition on $C S$. Hence, $U$ has too low an incentive to favor competition from a social viewpoint. When $D_{i}$ makes the offers, it ignores both the positive effect of an increase in competition (and production) to consumers and the negative effect to downstream firms. The additional fixed cost of servicing one more firm is borne by the downstream firms, and it benefits $U$ even though the associated cost of opening an additional line of production is higher than the positive effect on consumers of increasing production to $Q(n+1)$.

Corollary 1 The upstream firm's incentive to favor competition is lower than that of a social planner when the upstream firm has all bargaining power and 
can be either lower or higher when the downstream firms have all bargaining power.

This result is to be contrasted with the analysis of market foreclosure in BW and HT. In these papers, the upstream firm's incentive to promote competition in vertically related markets is too low from a social viewpoint. Here, this need not be the case, which, of course, potentially has strong implications from a competition policy viewpoint.

\section{Vertical Integration}

Vertical integration is widely thought of as a way of imposing vertical restraints on vertically related firms. In this section, as in HT and RT, we view vertical integration as an opportunity for the upstream firm to overcome the (Coasian) commitment problem described in section 3 by restricting production ${ }^{13}$. We focus on the effect of downstream competition on the incentive for the upstream firm to vertically integrate one downstream firm.

For this purpose, we rule out the upstream firm's ability to pick the number of potentially active downstream firms in stage 1 , and we consider instead that stage 1 is a vertical integration decision. The upstream firm now has to take the number of potentially active downstream firms as given, but it can affect downstream competition through vertical integration ${ }^{14}$. We assume that the owner of a production unit's assets is entitled to all the returns generated by this unit (although profit sharing would be enough) and all the decision rights concerning production and trade involving this unit. Ownership will matter because of contract incompleteness. We followed the literature in assuming that no contract can be signed before the bargaining stage. Like Grossman and Hart (1986), BW and HT (where this assumption is discussed at length), the characteristics of the input may be difficult to write in a contract in advance.

For simplicity, we assume that $U$ merges with either 0 or 1 downstream firms. This may be either because a vertical structure with more than one 
downstream firm has to bear a prohibitively high agency cost or, as we shall now see, because monopolization and total foreclosure in equilibrium make only the integration of one firm profitable. Indeed, we first consider how vertical integration affects bargaining and production.

Vertical integration leads the upstream firm to monopolize the downstream industry by supplying its subsidiary only. To see this, denote by $q_{1}$ the quantity that the upstream firm sells to its downstream firm $D_{1}$. The quantity decisions after $U$ or $D_{i}(i \neq 1)$ made the offers both satisfy

$\left(q_{i}\right)_{1 \leq i \leq n} \in \arg \max \left[P\left(q_{1}+\sum_{j=2}^{n} q_{j}\right) q_{1}-c q_{1}-f(1)\right]+\sum_{i=2}^{n}\left[P\left(q_{-i}^{a}+q_{i}\right) q_{i}-c q_{i}-f(i)\right]$

where $q_{-i}^{a}$ denotes the quantity that downstream firm $D_{i}$ expects the upstream firm to sell to all other downstream firms (including $D_{1}$ ). The program is maximized for $q_{i}=0$ for any $i \in\{2, \ldots, n\}$, and $q_{1}=Q^{m}$ (note that this result does not depend on the cost of operating lines of production) $)^{15}$.

Since it can observe both its transactions with the other downstream firms and it obtains all the returns of the vertical structure (having a share $\beta$ would not affect the result), the upstream firm internalizes the negative externality of supplying other downstream firms on its subsidiary. Hence, nothing prevents it from supplying the monopoly quantity. The upstream firm can appropriate the whole industry surplus by supplying only the firm that it owns. This surplus is maximized under the monopoly quantity. There is monopolization and total foreclosure (here, the absence of an outside option for downstream firms is essential). The payoff to the integrated structure does not depend on the number of firms in the market.

We now study the effect of downstream competition on the upstream firm's incentive to vertically integrate one downstream firm. If the upstream firm has all bargaining power, its benefit from vertical integration, $U^{v i}-U^{n i}$, increases with $n$ since its payoff under non-integration, $U^{n i}$, decreases with $n$. If the 
downstream firms have all bargaining power, $U^{v i}-U^{n i}$ decreases with $n$ since $U^{n i}$ increases with $n$. When many firms are in the downstream market, the upstream firm's surplus is already quite high under non-integration and the profit increase under vertical integration is not so high. In contrast, when there are few downstream firms, the payoff under non integration may be so low that vertical integration is worthwhile.

Proposition 2 The upstream firm's incentive to integrate a downstream firm strictly decreases (resp. increases) with the number of downstream firms when downstream firms have (resp. the upstream firm has) all bargaining power.

In this model, vertical integration is always desirable to the upstream firm since it solves its commitment problem. However, vertical integration often comes with costs in practice. Following BW and HT, we could have assumed that a vertically integrated structure must bear some agency cost $A$ that a non integrated structure does not have to bear. Then, vertical integration would take place when the downstream industry is competitive (resp. concentrated) enough if the upstream firm's bargaining power is high (resp. low).

Assume now that downstream firms can enter at stage 0 at cost $E$ and that the decision to vertically integrate a downstream firm in stage 1 comes with a fixed cost $A$. Hence, entry affects the incentive to integrate and the expectation of vertical integration will in turn affect entry. The number of downstream firms in equilibrium is affected by the possibility of vertical integration.

Proposition 3 When both entry in the downstream industry in stage 0 and vertical integration in stage 1 are subject to fixed costs, there are values of these fixed costs such that the mere possibility of vertical integration can be a barrier to entry.

Proof: See Appendix.

When the upstream firm's bargaining power is high, a high entry cost implies that a few downstream firms enter. For appropriate values of $A$, the 
upstream firm is better off supplying a few non-integrated downstream firms and it opts for no integration. But the possibility of vertical integration may reduce the number of entrants enticed by a low entry cost: A potential entrant that would have made a positive profit in the absence of vertical integration may realize that entering would trigger vertical integration (with zero payoff to the downstream firms) and would thus prefer to stay out. Thus, the mere possibility of vertical integration can be a barrier to entry and can sustain profits in an industry. When the downstream firms have high bargaining power, there are values of $A$ such that a sufficiently low entry cost induces enough entry, and hence enough downstream competition to prevent vertical integration, but a high entry cost triggers vertical integration. This is because the concentrated downstream industry implies a low payoff to the upstream firm without integration. Hence, vertical integration will take place. Since this is anticipated by potential entrants, only one downstream firm actually enters the market.

Horizontal mergers and spin-offs may also prove to be a way to prevent vertical integration and market foreclosure. Assume that horizontal mergers and spin-offs (but not entry) are allowed in stage 0, each downstream firm requring a setup cost $E$ in order to be active after stage 0 . Assume further that the owners of two merging downstream firms share the profit equally and that two downstream firms resulting from a horizontal spin-off compete in quantities. Following the same reasoning as in the Proposition above, we obtain

Corollary 2 Horizontal integrations (when the upstream firm's bargaining power is high) or spin-offs (when the upstream firm's bargaining power is low) may take place in order to prevent vertical integration.

The downstream firms may strategically merge or separate in order to prevent vertical integration and market foreclosure. They may be better off either separating and weakening their bargaining position (and maybe duplicating fixed costs) or merging and reducing their market share. 
This result is consistent with the empirical literature whereby spin-offs and asset sales improve performance and hence discourage takeovers (John and Ofek (1995), Lang et al (1995), Maksimovic and Phillips (2001)). The hypothesis that spin-offs discourage takeovers is consistent with the fact that $\alpha$ is low, or more probably, as we shall see in the next section, that there is competition in the upstream segment as well. Empirical tests of spin-offs and horizontal mergers in industries with a concentrated vertically related segment may provide a proxy for this dominant firm's bargaining power.

Finally, vertical integration is not necessarily socially harmful, since a social planner would have to weigh the cost of monopolization with the benefits of saving on additional costs of opening lines of production. It follows from corollary 1 and the analysis of this section that

Corollary 3 When the upstream firm's bargaining power is high, the upstream firm's incentive to vertically integrate is too high from a social viewpoint. When the upstream firm's bargaining is low, the upstream firm may have either too high or too low an incentive for vertical integration. In particular, some socially desirable vertical integrations may not take place, i.e. they may not be privately profitable, when the upstream firm's bargaining power is low.

This result is to be contrasted with BW and HT who find that downstream competition results in an excessive tendency towards vertical integration. Non desirable integration may appear in their model because the benefits from the vertical merger go to the merging parties, while the consumers are either worse off or unaffected ${ }^{16}$. Here, when downstream firms have high bargaining power, vertical integration and monopolization lead to savings on costs of opening lines of production which would have been costly from a social viewpoint if they were higher than the increase in consumer's surplus ${ }^{17}$. 


\section{The Effect of Upstream Competition}

Assume now that there are two upstream firms $U_{p}, p \in\{1,2\}$, both of them with a marginal cost of production $c$ and a cost of opening lines of production $f(\cdot)$. The game is as before, with the stage 2 bargaining game as follows: With probability $\alpha$ (resp. $1-\alpha$ ), both upstream (resp. downstream) firms make take-it-or-leave-it offers. Then each downstream firm (resp. each upstream firm) decides whether or not to accept the offer.

We show that our competition effect pertains for any distribution of bargaining power, while the rent reduction effect vanishes.

Proposition 4 The upstream firms supply the downstream firms with the Cournot quantities $q^{C}(n)$. The transfers satisfy $T_{p, i}\left(q^{C}(n)\right)=c q^{C}(n)+f(n / 2)$ if $n$ is even and $T_{p, i}\left(q^{C}(n)\right)=c q^{C}(n)+f((n+1) / 2)$ if $n$ is odd. The payoff to the upstream firms are unaffected by the distribution of bargaining power. Upstream firms are better off facing a more competitive downstream industry.

Proof: See Appendix.

As in section 3, the upstream firms cannot commit to supply quantities other than the Cournot quantities. When the upstream firms make offers, they compete in Bertrand with differentiated costs. The lower cost associated with having supplied fewer downstream firms confers a strategic advantage that enables the upstream firms to make positive profit on inframarginal downstream firms. The higher the number of dowsntream firms, the more downstream firms they supply and the higher the profit they make when supplying an inframarginal downstream firm. This implies that all the results we had in section 3 with $\alpha=0$ now hold for any distribution of bargaining power. In particular, the incentive to encourage competition in the downstream market may be higher than that of a social planner.

In this setting upstream firms may be tempted to reduce the aggregate quantity sold to the downstream market by selling downstream firms a quantity 
that is just high enough to ensure that these downstream firms do not buy from the other upstream firm. However, the market-by-market bargaining rules out this possibility: Since upstream firms cannot affect the other downstream firms' beliefs about aggregate downstream industry output, the best strategy is to offer each downstream firm the quantity that maximizes the surplus from the bilateral relationship, that is the Cournot quantity.

With vertical integration, however, it turns out that such a strategy to restrict downstream industry output is possible when the costs of opening lines of production are high enough and when the number of downstream firms is low enough. The vertical integration game with two upstream firms leads to the following results:

Proposition 5 If both upstream firms integrate a downstream firm, then downstream industry output is arbitrarily close to the monopoly quantity if $n=2$ and the costs of opening lines of production are high enough, and it is the Cournot duopoly quantity for higher values of $n$. If only one upstream firm integrates a downstream firm, then the aggregate downstream industry output is arbitrarily close to the monopoly quantity if $n=2$ and the costs of opening lines of production are high, and $Q^{C}(n)$ for higher values of $n$.

As in the case of the monopolistic upstream firm, the supply of nonintegrated downstream firms in the full-integration case is driven to zero by the fact that the upstream firms now internalize the negative externality of supplying other downstream firms. When the costs of opening lines of production are small enough, each upstream firm takes as given that the other upstream firm will also supply its downstream segment, which generates the Cournot duopoly result. Hence, full integration enables upstream firms to extend their market power to the downstream industry. When the costs of opening lines of production are high enough, they may enable an upstream firm to exclude the other upstream firm and to reduce downstream industry output. An upstream firm may make an offer to the downstream firm owned by its competitor that 
discourages this competitor from supplying its subsidiary. Such an offer would lead to the choice of a quantity that is just high enough to ensure that the quantity that the upstream competitor would offer does not compensate the cost of opening a line of production. Although this preemptive strategy is a dominated strategy when $n$ is high, it may be optimal for low values of $n$ when costs of opening lines of production are high.

The intuition in the partial integration case is as follows. Say that $U_{1}$ owns one downstream firm and that $U_{2}$ does not. Given this "partially integrated" market structure, $U_{1}$ would be tempted to restrict production and to supply its downstream firm, say $D_{1}$, only. However, supplying only $D_{1}$ would leave $U_{2}$ with the possibility to supply the other downstream firms, including those for which $U_{1}$ has a lower cost of opening another line of production. If $U_{2}$ 's cost of opening lines of production is high enough, $U_{1}$ may then offer $D_{i, i \neq 1}$ a contract whereby $D_{i}$ will buy a quantity that is just high enough to induce $D_{i}$ to reject any offer from $U_{2}$. Anticipating that it will appropriate the whole downstream industry profit, $U_{1}$ can pay a higher transfer than $U_{2}$. If the cost of opening lines of production is arbitrarily close to zero, however, $U_{2}$ can make offers arbitrarily close to $c q_{i}$, and $U_{1}$ cannot exclude transactions between $U_{2}$ and $D_{i}$. This implies that all downstream firms will be able to order $q^{C}(n)$.

In the full integration case, we obtain that with low fixed costs or many downstream firms, upstream firms can extend their market power as in the previous papers on foreclosure such as HT. In addition, sufficiently high fixed costs may induce monopolization instead of a duopoly outcome when there are two downstream firms. Our results also indicate that the partially integrated structure is as competitive as the non-integrated structure when there are many downstream firms or when costs of opening lines of production are low, but that it leads to a monopolistic outcome as the fully integrated structure when there are two downstream firms and high fixed costs. These results did not obtain in previous papers such as HT and BW since they only assumed constant 
marginal costs of production, without costs of opening lines of production.

Finally, the interactions between vertical integration and competition in the downstream industry are similar to those in section 4 with a low $\alpha$. The incentive for vertical integration is decreasing in the number of downstream firms, the possibility of vertical integration can be a barrier to entry when the downstream industry is concentrated, and horizontal spin-offs may take place to discourage anti-competitive vertical mergers. This is consistent with the empirical evidence on asset sales (John and Ofek (1995), Lang et al (1995), Maksimovic and Phillips (2001)).

\section{Concluding Remarks}

This paper analyzed a monopolist's choice of how many trading partners it would like to have when bargaining over optimal contracts. In contrast with the literature on market foreclosure, which describes how the use of vertical restraints both induce and enable a firm with significant market power to extend its market power to vertically related segments, we pointed out that such a firm may be tempted to favor competition among trading partners in order to improve its negotiation position. Its incentive to favor competition may actually be higher than that of a social planner. This incentive to promote competition may also hold when conditional contracts (and in particular exclusive dealing agreements) are allowed. For instance, in the case of several production periods, the upstream firm may still want to supply a number of downstream firms to make sure that there is enough downstream competition remaining in each period. In the presence of upstream competition, the form of the transfer function offered by the upstream firm is a two-part tariff whatever the distribution of bargaining power. Upstream firms are unambiguously better off with more downstream competition. We further discussed the anticompetitive effects of vertical integration, and the interactions between vertical integration and downstream competition. We also pointed out that in presence 
of upstream competition partial integration may lead to monopolistic outcomes with two downstream firms and high fixed costs, and to competitive outcomes otherwise.

In practice, anti-trust rulings sometimes prohibit vertical integration or dismantle a vertical structure in order to encourage downstream competition. Over the past few years, the most hotly debated case of the pros and cons of vertical separation has certainly been Microsoft. There is little discussion that Microsoft has a dominant position in the operating systems for personal computers. Although spllitting Microsoft into separate entities would certainly reduce its ability to monopolize vertically-related segments, its ability to reduce competition with other vertical restraints does not appear to be fully understood. It may be argued that in high-technology industries, where innovation implies the possible appearance of a competitor, a dominant firm's bargaining power is limited. This would arguably be the case of a vertically separated Microsoft. An implication of our analysis would then be that a vertically separated Microsoft, where the operating system company would be banned from writing exclusive dealing contracts with downstream application companies, might be tempted to create competition in vertically related markets in order to improve its bargaining position in spite of its dominant position. We believe that this argument would be robust to the network effects and other specificities of the Microsoft case. More generally, our paper shows that the incentives for a monopolist to extend its market power to vertically related segments may be more limited than the previous literature has suggested.

We believe that this paper could lead to a number of potential extensions. First, the limits of a monopolist's incentives to extend its monopoly power to vertically related segments should be better understood. A better understanding of these limits may be important in competition policy. Next, while we assumed that vertical integration is irreversible, vertical mergers and spin-offs may take place sequentially. This paper suggests that a shift in the demand 
curve or a change in the competitive environment may trigger such mergers or spin-offs. This could be a starting point towards an analysis of the dynamics of integration and of its interactions with the competitive environment. Finally, most assumptions of our paper seem reasonable to analyze financial intermediation. The secrecy of transactions is an important factor of many financial contracts. Interbank loans suggest that banks' cost of capital is often a linear function of this capital, while fixed fees may be here to pay for labour and operating costs. Our results suggest that an investor with significant market power and high bargaining power would tend to offer more equity-like contracts, while the same investor with low bargaining power or competing investors would tend to offer loan or debt contracts with fixed fees. Fixed fees, as opposed to the linear part of the two-part tariffs (e.g. interest rates), would be an important determinant of upstream firms' profits and they should be looked at carefully when examining the effective level of competition. 


\section{Appendix}

\section{Proof of Proposition 1.}

We first assume that $U$ has all bargaining power. The upstream firm makes simultaneous take-it-or-leave-it offers to all downstream firms which satisfy

$$
\begin{array}{cl}
\max _{\left.T_{U, i}(\cdot)\right)} & {\left[\sum_{i=1}^{n} T_{U, i}\left(q_{i}\right)-c q_{i}-f(i)\right.} \\
\text { s.t. } & P\left(q_{-i}^{a}+q_{i}\right) q_{i} \geq T_{U, i}\left(q_{i}\right) \\
& 0 \leq q_{i} \in \arg \max P\left(q_{-i}^{a}+q_{i}\right) q_{i}-T_{U, i}\left(q_{i}\right) .
\end{array}
$$

where $q_{-i}^{a}$ stands for the anticipated aggregate quantity that will be produced by all downstream firms $j \neq i$. Constraint (5) is downstream firm $D_{i}$ 's incentive compatibility constraint. Clearly, each downstream firm's participation constraint (4) is binding. Anticipating the choice of $q_{i}$, the upstream firm offers a tariff $T_{U, i}(\cdot)$ which is limited by the secrecy of its transactions with the other downstream firms, but that leaves each downstream firm with zero utility if the quantity preferred by the upstream firm is chosen, and a negative utility otherwise. Therefore, the quantity chosen by each downstream firm satisfies

$$
\begin{aligned}
q_{i} & \in \arg \max \sum_{j=1}^{n} P\left(q_{-j}^{a}+q_{j}\right) q_{j}-c q_{j} \\
& \equiv R_{i}^{C}\left(q_{-i}^{a}\right)
\end{aligned}
$$

where $R^{C}$ stands for the reaction function of a standard Cournot game. It should be noted that each downstream firm only cares about its own transaction with the upstream firm, since by assumption a change in a quantity chosen does not affect other downstream firms' beliefs. As in standard Cournot games (Tirole (1988) ch. 5), $q_{-i}^{a}$ is then determined to be equal to $\frac{n-1}{n} Q^{C}$ through rational expectations, where $Q^{C}=n q_{i}=n q^{C}$ turns out to be the aggregate 
Cournot quantity. Then, $U$ appropriates the full industry surplus and gets a total transfer $T\left(Q^{C}\right)=P\left(Q^{C}\right) Q^{C}$.

It should be noted that the maximization over the pair $\left\{q_{i}, T_{U, i}\right\}$ yields the same result. This is because once we substitute for the transfer in the maximand, we only maximize through quantity.

We now investigate the case where downstream firms have all bargaining power. Each downstream firm makes a take-it-or-leave-it offer (to the upstream firm) which satisfies

$$
\begin{array}{cl}
\max _{\left.T_{i, U}(\cdot)\right)} & P\left(q_{-i}^{a}+q_{i}\right) q_{i}-T_{i, U}\left(q_{i}\right) \\
\text { s.t. } & q_{i} \in \arg \max P\left(q_{-i}^{a}+q_{i}\right) q_{i}-T_{i, U}\left(q_{i}\right) \\
& T_{i, U}\left(q_{i}\right)-c q_{i}-f\left(l^{a}+1\right)+\sum_{j=1, j \neq i}^{l^{a}}\left[T_{j}\left(q_{j}^{a}\right)-c q_{j}^{a}-f(j)\right] \\
& \geq \sum_{k=1, k \neq i}^{m^{a}}\left[T_{k}\left(q_{k}^{a}\right)-c q_{k}^{a}-f(k)\right]
\end{array}
$$

where the subscript $a$ on quantities hold for quantities that are expected to be sold to other downstream firms, and $l^{a}\left(\operatorname{resp} m^{a}\right)$ hold for the number of other downstream firms expected to be supplied by the upstream firm if $D_{i}$ 's offer is accepted (resp. rejected). The latter constraint, which is binding, implies that the transfer corresponding to the quantity chosen by downstream firm $D_{i}$ can be written $T_{i, U}\left(q_{i}\right)=c q_{i}+A_{i}(n)$, where $A_{i}(n)$ is independent of $q_{i}{ }^{18}$. This implies that each downstream firm will buy and transform a quantity satisfying

$$
q_{i} \in \arg \max P\left(q_{-i}^{a}+q_{i}\right) q_{i}-c q_{i}-A_{i}(n)=R^{C}\left(q_{-i}^{a}\right),
$$

Since this holds for any $i \in\{1, \ldots, n\}$, this implies that $l^{a}=m^{a}=n=1$, and that each downstream firm will order and sell the Cournot quantity $q^{C}$. Rewriting (9) leads to $T\left(q_{i}\right)=c q_{i}+f(n)$, which gives the result. As in the case where the upstream firm made the offers, it is easy to see that contract offers 
on pairs quantity-transfers (taking the first-order derivatives with respect to $q_{i}$ and $\left.T_{i, U}\right)$ that bargaining over these pairs results in quantities and transfers identical to those found here ${ }^{19}$.

\section{Proof of Proposition 3.}

The downstream firms expect to have zero payoff if there is vertical integration in stage 1 . Hence, they only enter in stage 0 if they do not expect vertical integration and if $(1-\alpha)\left[P\left(Q^{C}\right) q^{C}-c q^{C}-f(n)\right] \geq E$ (note that this requires that $\alpha$ be strictly lower than 1 ). On the other hand, $U$ only integrates a downstream firm if $U^{v i}-U^{n i}(n) \geq A$.

First consider the case where the upstream firms have high bargaining power, which implies that $U^{v i}-U^{n i}(n)$ increases in $n$. When $E$ and $A$ are such that the level of downstream firms that enter makes it unattractive to vertically integrate one downstream firm, the possibility of vertical integration does not affect market structure. For instance, these values are such that a few downstream firms enter, $U$ does not lose much from downstream competition., and $A$ is high enough to ensure that the upstream firm is better off supplying a few non-integrated downstream firms. But the possibility of vertical integration may reduce the number of entrants enticed by a low entry cost: Call $p$ the smallest number of downstream firms that would trigger vertical integration given integration cost $A$. Assume that absent vertical integration $q>p$ downstream firms would have entered given entry cost $E$. Then the $(p+1)^{t h}$ downstream firm will realize that entering will trigger vertical integration, and hence a zero payoff. Hence, it will choose to not enter, and there will be no vertical integration.

When the downstream firms have high bargaining power, $U^{v i}-U^{n i}(n)$ decreases in $n$. Call $p$ the smallest number of downstream firms such that there is no vertical integration given $A$. If $E$ is so low that $q>p$ firms wish to 
enter, then the possibility of vertical integration does not affect the analysis. If, however, $E$ is so high that $q<p$ firms would enter absent vertical integration, the downstream firms will realize that entering triggers vertical integration. Hence, all downstream firms but one choose to stay out.

\section{Proof of Proposition 4.}

Given that an upstream firm $U_{p}$ must incur a fixed cost in order to supply a downstream firm, we can restrict the analysis to the case where each downstream firm buys inputs from only one upstream firm. The offers made by upstream firm $U_{p}$ satisfy

$$
\begin{aligned}
\max _{T_{p, i}(\cdot)} & {\left[\sum_{i=1}^{n} T_{p, i}\left(q_{p, i}\right)-c q_{p, i}-f(i)\right] } \\
\text { s.t. } & P\left(q_{-i}^{a}+q_{p, i}\right) q_{i}-T_{p, i}\left(q_{p, i}\right) \geq P\left(q_{-i}^{a}+q_{-p, i}^{a}\right) q_{i}-T_{-p, i}^{a}\left(q_{-p, i}^{a}\right) \\
& 0 \leq q_{p, i} \in \arg \max P\left(q_{-i}^{a}+q_{p, i}+q_{-p, i}\right) q_{p, i}-T_{p, i}\left(q_{p, i}\right) \\
& T_{p, i}\left(q_{p, i}\right)-c q_{p, i}-f(i) \geq 0 .
\end{aligned}
$$

where superscript $a$ stands for $D_{i}$ 's expectation about quantities sold to other downstream firms, and upstream firm $U_{p}$ 's expectation about $U_{p}$ 's offer. Constraint (12), which states that downstream firm $D_{i}$ will only accept $U_{p}$ 's offer if this leaves $D_{i}$ with a utility at least as high, is binding. Plugging the transfer in the maximand, it follows that each downsream firm will be supplied the Cournot quantity.

The transfers are then determined by noting that (12) is restricted to a competition in transfers taking the Cournot quantities as given (which iimplies that the program is identical to offers of pairs $\left.\left\{q_{p, i}, T_{p, i}\right\}\right)$. Upstream firms compete in the Bertrand sense with differentiated costs. The upstream firm that will make the better offer is the one with the lower cost, i.e. the one that has supplied (weakly) fewer downstream firms, and the transfer offered will then by the other upstream firm's cost of supplying $D_{i}$. Hence, the offers 
satisfy $T_{p, i}\left(q_{p, i}\right)=c q_{p, i}+f(n / 2)$ if $n$ is even and $T_{p, i}\left(q_{p, i}\right)=c q_{p, i}+f((n+1) / 2)$ if $n$ is odd.

An analysis of the offers made by the downstream firms that is similar to that of the proof of Proposition 1 indicates that (1) each downstream firm will buy the Cournot quantity, (2) their offer will be $f\left(n^{a}+1\right)+c q_{i}$, where $n^{a}$ is the number of other downstream firms that the upstream firm that has supplied the fewer downstream firms is expected to have supplied, and (3) half of the downstream firms are supplied by each upstream firm if $n$ is even, and $(n-1) / 2$ downstream firms will be supplied by each upstream firm (while the $n^{\text {th }}$ firm will randomize) if $n$ is odd.

\section{Proof of Proposition 5.}

Full integration: First assume that no upstream firm can benefit from supplying the downstream segment that is owned by its competitor in order to reduce downstream industry output. In particular, this is true when $f(i) i \in\{1, \ldots, n\}$ is arbitrarily small, which brings us back to HT's framework. $U_{p}$ 's offers satisfy (denoting by $D_{p}$ its downstream segment)

$$
\begin{array}{ll}
\max _{T_{p, i}(\cdot), i \neq p} & P\left(q_{p, p}+\sum_{i=1, i \neq p}^{n} q_{p, i}+\sum_{j=1}^{n} q_{-p, j}^{a}\right) q_{p, p}-c q_{p, p}-f(1) \\
& +\left[\sum_{i=1, i \neq p}^{n} T_{p, i}\left(q_{p, i}\right)-c q_{p, i}-f(i)\right] \\
\text { s.t. } \quad & P\left(q_{-i}^{a}+q_{p, i}\right) q_{i}-T_{p, i}\left(q_{p, i}\right) \geq P\left(q_{-i}^{a}+q_{-p, i}^{a}\right) q_{-p, i}-T_{-p, i}^{a}\left(q_{-p, i}^{a}\right) \\
& 0 \leq q_{p, i} \in \arg \max P\left(q_{-i}^{a}+q_{p, i}+q_{-p, i}\right) q_{p, i}-T_{p, i}\left(q_{p, i}\right) \\
& T_{p, i}\left(q_{p, i}\right)-c q_{p, i}-f(i) \geq 0 .
\end{array}
$$

The binding participation constraint implies that the problem boils down to

$$
\max _{q_{p, i}} P\left(q_{p, p}+\sum_{i=1, i \neq p}^{n} q_{p, i}+\sum_{j=1}^{n} q_{1, j}^{a}\right) q_{p, p}-c q_{p, p}-f(1)
$$




$$
+\left[\sum_{i=1, i \neq p}^{n} P\left(q_{-i}^{a}+q_{p, i}\right) q_{i}-c q_{p, i}-f(i)\right]
$$

which leads to

$$
\begin{aligned}
P^{\prime}\left(q_{p, p}+\sum_{i=1, i \neq p}^{n} q_{p, i}+\sum_{j=1}^{n} q_{-p, j}^{a}\right) q_{p, p} & +P\left(q_{p, p}+\sum_{i=1, i \neq p}^{n} q_{p, i}+\sum_{j=1}^{n} q_{-p, j}^{a}\right)-c=0 \\
P^{\prime}\left(q_{p, p}+\sum_{i=1, i \neq p}^{n} q_{p, i}+\sum_{j=1}^{n} q_{-p, j}^{a}\right) q_{1} & +P\left(q_{p, i}+\sum_{k=1, k \neq i}^{n} q_{p, k}^{a}+\sum_{j=1}^{n} q_{-p, j}^{a}\right)-c \\
+P^{\prime}\left(q_{p, i}+\sum_{k=1, k \neq i}^{n} q_{p, k}^{a}+\sum_{j=1}^{n} q_{-p, j}^{a}\right) q_{p, i} & =0
\end{aligned}
$$

This implies that $q_{p, p}=R^{C}\left(q_{-p,-p}^{a}+\sum_{j=1}^{n} q_{-p, j}^{a}\right)$ and $q_{p, i}=0 \forall i \neq p$. Proceeding similarly with firm $U_{p}$ implies that each upstream firm supplies its downstream firm with the Cournot duopoly quantity.

Now consider the possibility for an upstream firm, say $U_{1}$, to make offers to $D_{2}$ in an attempt to prevent $U_{2}$ from trading so as to reduce downstream industry output. This may be a concern, for instance, when $f(n)=f(n-$ 1) $+\epsilon=f(1)+n \epsilon=\left[P\left(n q^{C}\right)-c\right] q^{C}-\epsilon$, with $\epsilon$ arbitrarily small. With such a distribution of costs, the cost disadvantage for an upstream firm that supplies one or several downstream firms compared to an upstream firm that did not supply any downstream firm is arbitrarily small, and the cost of opening lines of production is so large that an upstream firm must sell the Cournot quantity to a downstream firm in order to meet this cost.

Then the best possible transaction between $U_{2}$ and $D_{2}$ leads to a quantity no lower than $q_{2}$, which leaves $U_{2}$ with $\pi_{2}=\left[P\left(q_{-i}^{a}+q_{2}\right)-c\right] q_{2}-f(1)$. $U_{1}$ may be tempted to offer a contract that would induce $D_{2}$ and $U_{2}$ to not engage in such a transaction. This can be done by making an offer that leaves $U_{2}$ with a payoff marginally higher than $\pi_{2}$. A quantity $q_{1, i}$ such that $R^{C}\left[q_{-i}^{a}\right]=$ $q^{C}(n)+q_{1, i}+\epsilon$ and $\left[P\left(q_{-i}^{a}+q_{1, i}\right)-c\right]\left(q^{C}(n)-q_{1, i}\right)=f(1)+\epsilon$ achieves this goal. Similarly, $U_{2}$ may be tempted to supply other non-integrated downstream firms, so $U_{1}$ 's strategy requires $U_{1}$ to supply the other downstream firms with quantities that are also just enough to discourage them from accepting the 
best possible offers from $U_{2}$. As before, with the high costs of opening lines of production, $U_{2}$ 's offers would require the downstream firms to buy the Cournot quantity $q^{C}(n)$. Hence $U_{1}$ 's preemptive strategy requires $U_{1}$ to offer a menu whereby each non-integrated downstream firm orders from $U_{1}$ a quantity such that it is not tempted to buy $q^{C}(n)$ from $U_{2}$ and whereby it is better off accepting the offer from $U_{1}$ than $U_{2}$ 's best possible offer, i.e. $f(1)+c q^{C}$. However, this strategy requires $U_{1}$ to bear duplicated costs of opening lines of production, and it is dominated by the non-preemptive strategy when $n$ is large. More generally, this strategy can only be worthwhile if the actual aggregate downstream industry output is no higher than the Cournot duopoly quantity. In particular, when $n=2, U_{1}$ will choose $q_{1}=Q^{m}$ and $q_{\epsilon}$ arbitrarily close to 0 .

Partial integration: Say that $U_{1}$ is integrated, but $U_{2}$ is not. Proceeding as in the full integration case, we obtain $q_{1,1}=R^{C}\left(\sum_{i=2}^{n} q_{p, i}+\sum_{j=1}^{n} q_{-p, j}^{a}\right)$. The two upstream firms now have different objectives. $U_{1}$ would ideally like to restrict downstream industry output to $Q^{m}$, while $U_{2}$ is always willing to supply each downstream firm with $q^{C}(n)$. Here again, $U_{1}$ may be tempted to make an offer to $D_{i, i \neq 1}$ that induces $D_{i}$ to accept its offer and to reject any offer by $U_{2}$.

$U_{1}$ 's ability to exclude transactions between $U_{2}$ and $D_{i}$ is all the higher as $f(i)$ is high. First consider the extreme case where $f(i)$ are arbitrarily small. Then the best offer that $U_{2}$ can make to $D_{i, 1 \neq 1}$ is a menu $T_{2, i}(\cdot)$ whereby $T_{2, i}\left(q_{2, i}\right)=c q_{2, i}$. Hence, whatever attempt by $U_{1}$ to make an offer to $D_{i, 1 \neq 1}$ to restrict its output will be undermined by $D_{i}$ 's possibility to order any quantity from $U_{2}$ that $U_{1}$ did not offer to sell at competitive terms. The negligible costs of opening lines of productions make $U_{1}$ unable to prevent $D_{i}$ from buying its desired quantity from $U_{2}$. The equilibrium quantity is then the downstream firms' preferred quantity, that is the Cournot quantity $q^{C}(n)$. 
Now focus on the other extreme case where $f(n)=f(n-1)+\epsilon=f(1)+$ $n \epsilon=\left[P\left(n q^{C}\right)-c\right] q^{C}-\epsilon$, with $\epsilon$ arbitrarily small. Then the best offer that $U_{2}$ can make to $D_{i}$ elicits a quantity no lower than $q^{C}(n)$ against a transfer $f(1)+c q^{C}$, which leaves $D_{i}$ with $\pi_{2}=\left[P\left(q_{-i}^{a}+q^{C}(n)\right)-c\right] q^{C}(n)-f(1)$ and $U_{2}$ with 0 . However, if $D_{i}$ accepts this offer, $U_{1}$ will only make a Cournot profit. $U_{1}$ would be better off offering a contract that would induce $D_{i}$ to rule out $U_{2}$ 's offer. This can be done by making an offer that leaves $D_{i}$ with a payoff that is marginally higher than $\pi_{2}$ and that induces $D_{i}$ to reject any offer from $U_{2}$. A quantity $q_{\epsilon}$ such that $R^{C}\left[q_{1}+(n-2) q_{\epsilon}\right]=q^{C}(n)+q_{\epsilon}+\epsilon$ and $\left[P\left(q_{1}+(n-1) q_{\epsilon}\right)-c\right]\left(q^{C}(n)-q_{\epsilon}\right)=f(1)+\epsilon$ achieves this goal. In particular, these two constraints are satisfied for $q_{1}=(n-1) q^{C}(n)$ and $q_{\epsilon}=0$, but if this strategy of bearing duplicated costs to supply all downstream firms is not dominated, i.e if $n$ is not too high, $q_{1}$ will generally be lower than $(n-1) q^{C}(n)$ since $U_{1}$ may be tempted to decrease aggregate output by decreasing $q_{1}$ and by increasing $q_{\epsilon}$. Hence, the higher $n$, the higher the downstream industry output, and the higher the total cost of opening lines of productions to $U_{1}$. When $n$ is high enough, this preemptive strategy is dominated by the strategy of supplying $D_{1}$ only and refraining from bearing additional costs of opening lines of production. When $n=2$, however, $U_{1}$ will choose $q_{1}=Q^{m}$ and $q_{\epsilon}$ arbitrarily close to 0 . 


\section{Notes}

${ }^{1}$ The reader can also refer to Riordan and Salant (1994) for an interesting model on how vertical integration affects the competitive structure in video markets, and to McLaren (2000) for an analysis of the asset specificity problem in vertically related markets.

${ }^{2}$ The strict concavity of the inverse demand function serves to insure a unique pure strategy Cournot equilibrium.

${ }^{3}$ One may argue that if courts could observe the number of active downstream firms, they could infer that upstream sales were made. However, another (more costly) source of input would ensure that aggregate downstream production would not be a signal to a court that the upstream firm has entered into a sales agreement with some downstream firms.

${ }^{4}$ Any other motive for the upstream firm to not be willing or able to commit to supply only a limited amount to the industry would do. For instance, allowing for several production periods might induce the upstream firm to keep competition to play the downstream firms against one another in a "once out always out" setup.

${ }^{5}$ There are a number of reasons for which an upstream monopolist may not have all the bargaining power. For example, the upstream firm may be more eager to reach an agreement if the value of its input decreases over time or if there is some probability that a competing upstream firm will enter the market. The results in section 5 indicate that our qualitative results would obtain if we assumed that the upstream firm had all bargaining power if it remained alone in the industry (which would occur with probability $\alpha$ ), but that a competing upstream firm could enter the industry with probability $1-\alpha$.

${ }^{6}$ Our results would not be affected if firms bargained over the pair $\left\{q_{i}, T_{i}\right\}$. Formally (also see the Appendix), maximizing over $\left\{q_{i}, T_{i}\right\}$ leads to exactly the same transfers and quantities as we derive throughout the paper. When the downstream firms make the contract offers, they effectively choose both the tariffs and then the quantity they buy. This is equivalent to having them choose both simultaneously. When the upstream firm makes the contract offer, the equivalence comes from the fact that $U$ anticipates perfectly the quantity chosen by each downstream firm, and it leaves each downstream firm at its reservation utility for this quantity. Hence, without loss of generality, firms can be viewed as bargaining over a fixed quantity and a transfer payment.

${ }^{7}$ Given that transformation costs are low relative to the upstream firm's production cost, it is well-established that the downstream firms will transform all the units of input that they bought and market all the corresponding units of output (see Tirole (1988), ch. 5).

${ }^{8}$ Suppose that all downstream firms but $D_{i}$ had agreed that $D_{j}, j \neq i$ would buy $Q^{m} / n$. Then $U$ and $D_{i}$ would agree on a quantity $q_{i}=\arg \max \left[P\left(\frac{n-1}{n} Q^{m}+q\right)-c\right] q=R^{C}\left(\frac{n-1}{n} Q^{m}\right)>$ $Q^{m} / n$, where the Cournot reaction function satisfies $-1<\left(R^{C}\right)^{\prime}<0\left(\left(R^{C}\right)^{\prime}=-\left(P^{\prime}+\right.\right.$ $\left.Q P^{\prime \prime}\right) / 2 P^{\prime}+q P^{\prime \prime} \in(-1,0)$ since $P^{\prime}<0$ and $\left.P^{\prime \prime}<0\right)$. This commitment problem is analogous to the Coasian durable good pricing problem in many respects, with the number of firms playing the same role as the number of periods in the durable good monopoly case.

${ }^{9}$ Our approach in this section could also be seen as a principal-agent relationship in the style of Maskin and Tirole (1992) where the principal performs hidden actions (the sale to other downstream firms). Given the degree of competition in the downstream market, the upstream firm's hidden action enters the downstream firms' objective function. Here, as soon as $n \geq 2$, the upstream firm is strictly worse off than if the downstream firms could observe its action. 
${ }^{10}$ This result is qualitatively close to that in Stole and Zwiebel (1996a, 1996b), where the authors develop a non-cooperative multilateral dynamic bargaining game applied to intrafirm bargaining. Our approach is very different, though, because we analyze bargaining over optimal contracts and competition, but with a more stylized bargaining game.

11 This effect is absent in BW because they assumed no cost for the upstream firm. In $\mathrm{HT}$, the offers are always made by the upstream firms and this effect is ignored.

${ }^{12} \mathrm{It}$ appears that the commitment problem that comes from the secrecy of transactions and from our simple cost structure enables downstream firms to make money at $U$ 's expense. In particular, if the convex production cost is $C(Q)$, an offer $C(Q)-C\left(\frac{n-1}{n} Q\right)$ by each downstream firm would not be an equilibrium: One downstream firm could offer a transfer $n\left[C(Q)-C\left(\frac{n-1}{n} Q\right)\right]+\epsilon$ against the total Cournot quantity. The downstream firm could then produce the monopoly quantity, as this offer would induce $U$ to reject all other offers $C(Q)-C\left(\frac{n-1}{n} Q\right)$ that would be lower than the cost of producing other units. Downstream firms would tend to compete in Bertrand for schedules, and there would be no equilibrium in which downstream firms would make a profit as soon as $n \geq 2$. The intuitive outcome that each firm offers the supplier's incremental cost of production (which increases with other firms' production because the marginal cost increases) would require different specifications of the game, such as capacity constraints or infinitely repeated contract offers.

13 A number of examples can be used to document this argument. See, for instance, Brandenburger and Nalebuff's (1996) description of how Nintendo could build its success on voluntary shortages of video games and video game systems after the mid-1980s because of a dominating position on the segement of video game systems and of its ownership of game-developing subsidaries (pp. 111-118).

${ }^{14}$ Another interpretation of this is that when both options are available to the upstream firm there is a complementarity in the joint decision to vertically integrate and to choose the number of downstream firms.

15 The result obtains from the first-order condition $P^{\prime} q_{1}+P-c=0, P^{\prime} q_{i}=0$. The fact that downstream firms make zero profit if not bought implies that they compete in prices to be bought. Hence, at the vertical integration stage, the acquisition cost is zero.

${ }^{16}$ Kühn and Vives (1999) study a model with product variety and with upstream monopoly and downstream monopolistic competition. They identify conditions on consumer preferences under which vertical mergers are welfare improving or welfare reducing.

${ }^{17}$ Slightly modified setups would have led us to the result that some socially desirable vertical integrations may not take place when the upstream firm's bargaining power is high as well. For instance, when $U$ invests in design (the inverse demand curve $P(e, Q)$ satisfying $\left.P_{e}>0, P_{e, Q}>0\right)$, the consumer appropriates part of the surplus created by the upstream firm's investment, and the incentive to vertically integrate can be too low relative to the social optimum. When the upstream firm's bargaining power is high, monopolization after vertical integration may increase investment. Consumer surplus may be either higher or lower since consumers get a smaller share of a larger pie. Since $U$ ignores the positive effect of higher investment on consumer surplus, the incentive for monopolization/vertical integration may be either too high or too low from a social viewpoint.

${ }^{18}$ In our setup, all units bought by downstream firms will be used. This is why we did not have to formally distinguish between the number of units bought and the number of units sold by downstream firms. 
${ }^{19}$ Note that we did not determine the function $T_{i, U}(\cdot)$ for other values than $q^{C}$. For other quantities, the transfers only need to satisfy the incentive compatibility constraints. 


\section{REFERENCES}

Aghion, P., and P. Bolton, 1987, "Contracts as a Barrier to Entry", American Economic Review, 77, 388-401.

Bernheim, B., and M. Whinston, 1986a, "Common Agency", Econometrica, 54, 923-42.

Bernheim, B., and M. Whinston, 1986b, "Menu Auctions, Resource Allocations, and Economic Influence", Quarterly Journal of Economics, 101, $1-31$.

Biais, B., D. Martimort and J. C. Rochet, 2000, "Competing Mechanisms in a Common Value Environment", Econometrica, 68, 799-837.

Bolton, P., and M. Whinston, 1991, "The "Foreclosure" Effects of Vertical Mergers", Journal of Institutional and Theoretical Economics, 147, 20726.

Bolton, P., and M. Whinston, 1993, "Incomplete Contracts, Vertical Integration, and Supply Assurance", Review of Economic Studies, 60, 121-48.

Brandenburger, A., and B. Nalebuff, 1996, Co-opetition, Doubleday.

Chemla, G., 2000, "Downstream Competition, Foreclosure, and Vertical Integration", Centre for Economic Policy Research Discussion Paper no. $264 \%$.

Grossman, S., and O. Hart, 1986, "The Costs and Benefits of Ownership: A Theory of Vertical and Lateral Integration", Journal of Political Economy, 94, 691-719.

Hart, O., and J. Tirole, 1990, "Vertical Integration and Market Foreclosure", Brookings Papers on Economic Activity, 205-76.

John, K., and E. Ofek, 1995, "Asset Sales and Increase in Focus", Journal of 
Financial Economics, 37, 105-26..

Katz, M., 1991, "Game-playing agents: unobservable contracts as precommitments", Rand Journal of Economics, 22, 307-28.

Klemperer, P., and M. Meyer, 1989, "Supply Function Equilibria in Oligopoly under Uncertainty", Econometrica, 57, 1243-78.

Kühn, K.-U., and X. Vives, 1999, "Excess Entry, Vertical Integration and Welfare", Rand Journal of Economics, 30, 575-603.

Lang, L, A. Poulsen and R. Stulz, 1995, "Asset Sales, Firm Performance, and the Agency Costs of Managerial Discretion", Journal of Financial Economics, 37, 3-37.

Maksimovic, V., and G. Phillips, 2001, "The Market for Corporate Assets: Who Engages in Mergers and Asset Sales and Are There Efficiency Gains?", Journal of Finance, 56, 2019-65.

Martimort, D., 1996, "Exclusive Dealing, Common Agency, and Multiprincipals Incentive Theory", Rand Journal of Economics, 27, 1-31.

Maskin, E., and J. Tirole, 1992, "The Principal-Agent Relationship with an Informed Principal, II: Common Values", Econometrica, 60, 1-42.

Matthewson, G., and R. Winter, 1984, "An Economic Theory of Vertical Restraints", Rand Journal of Economics, 15, 27-38.

McAfee, R. P., and M. Schwartz, 1993, "Opportunism in Multilateral Vertical Contracting: Nondiscrimination, Exclusivity and Uniformity", American Economic Review, 84, 210-30.

McLaren, J., 2000, "Globalization and Vertical Structure", American Economic Review, 90, 1239-54.

Ordover, J., G. Saloner and S. Salop, 1990, "Equilibrium Vertical Foreclosure", 
American Economic Review, 80, 127-142.

Posner, R., 2001, Antitrust law, Chicago and London: University of Chicago Press, Second edition

Rajan, R., 1992, "Insiders and Outsiders: The Choice Between Relationship and arm's-length Debt", Journal of Finance, 47, 1367-1400.

Rey, P., and J. Tirole, 1999, "A Primer on Foreclosure”, Handbook of Industrial Organization (forthcoming).

Riordan, M., and D. Salant, 1994, "Exclusion and Integration in the Market for Video Programming Delivered to the Home" Boston University, Industry Study Program Discussion Paper no. 51

Stole, L., and J. Zwiebel, 1996a, "Intra-firm Bargaining under Non-binding Contracts", Review of Economic Studies, 63, 375-410.

Stole, L., and J. Zwiebel, 1996b, "Organizational Design and Technology Choice under Intrafirm Bargaining", American Economic Review, 86, 195-222.

Tirole, J., 1988, The Theory of Industrial Organization, MIT Press. 